\title{
Laboratory Director
}

National Cancer Institute

\section{Source}

National Cancer Institute. Laboratory Director. NCI Thesaurus. Code C51829.

A person who plans, organizes, coordinates and oversees the overall operation of

laboratory activities. The laboratory director establishes policies and procedures that govern the utilization of community laboratory services, and ensures that the laboratory and support personnel receive the appropriate training associated with the work involved. 